\title{
GLUT-1 overexpression as an unfavorable prognostic biomarker in patients with colorectal cancer
}

\author{
Jing Yang ${ }^{1, *}$, Jing Wen ${ }^{2, *}$, Tian Tian ${ }^{3, *}$, Zhongsheng Lu ${ }^{1}$, Yao Wang ${ }^{4}$, Zikai Wang ${ }^{1}$, \\ Xiangdong Wang ${ }^{1}$, Yunsheng Yang ${ }^{1}$ \\ ${ }^{1}$ Department of Gastroenterology and Hepatology, Chinese PLA General Hospital, Beijing, China \\ ${ }^{2}$ Department of Gastroenterology and Hepatology, Chinese PLA 261 Hospital, Beijing, China \\ ${ }^{3}$ Nanlou Department of Respiratory Disease, Chinese PLA General Hospital, Beijing, China \\ ${ }^{4}$ Department of Immunology/Bio-therapeutic, Institute of Basic Medicine, Chinese PLA General Hospital, Beijing, China \\ *These authors have contributed equally to this work
}

Correspondence to: Yunsheng Yang, email: sunny301ddc@126.com

Keywords: meta-analysis, biomarker, colorectal cancer, survival, GLUT-1

Received: September 20, 2016

Accepted: December 20, 2016

Published: December 29, 2016

\section{ABSTRACT}

Background: Glucose transporter-1 (GLUT-1) exhibits altered expression in colorectal cancer (CRC). The aim of this study was to explore the association between GLUT-1 and survival conditions, as well as clinical features in CRC by meta-analysis.

Materials and Methods: Relevant studies were searched through predefined strategies, hazard ratios (HRs), odds ratios (ORs), and their $95 \%$ confidence intervals (CIs) were used as effective measures.

Results: A total of 14 studies with 2,077 patients were included in this metaanalysis. The results showed that GLUT-1 was not significantly associated with overall survival (OS) $(H R=1.28,95 \% C I=0.86-1.91, p=0.22)$ or disease-free survival (DFS) $(\mathrm{HR}=1.71,95 \% \mathrm{CI}=0.78-3.72, \mathrm{p}=0.179)$. However, subgroup analysis indicated that GLUT-1 was a significant biomarker for poor DFS in rectal cancer $(H R=2.47$, $95 \% \mathrm{CI}=1.21-5.05, \mathrm{p}=0.013)$. GLUT-1 expression was also found to be significantly correlated with the presence of lymph node metastasis $(n=8, O R=2.14,95 \% C I=1.66-$ $2.75, p<0.001)$, $T$ stage $(n=6, O R=1.73,95 \% C I=1.17-2.58, p=0.007)$, higher Dukes stage $(n=5, O R=2.92,95 \% C I=2.16-3.95, p<0.001)$, female sex $(n=4, O R=2.92$, $95 \% \mathrm{CI}=2.16-3.95, \mathrm{p}<0.001)$, and presence of liver metastasis $(n=3, O R=1.82,95 \%$ $\mathrm{CI}=1.06-3.12, \mathrm{p}=0.03$ ).

Conclusion: In conclusion, this meta-analysis showed that GLUT-1 was associated with poor DFS in rectal cancer (RC). Furthermore, GLUT-1 was also an indicator of aggressive clinical features in CRC.

\section{INTRODUCTION}

Colorectal cancer (CRC) is the third most prevalent cancer and the second leading cause of cancer-related death worldwide [1]. It is estimated that 1.36 million new cases and 693,900 deaths occurred in 2012 [2]. Although significant advances have been achieved in the treatment of CRC, the 5-year survival rate is $64 \%[3,4]$. Confounding this is that fact that about one-fifth of CRC patients are in metastatic disease at first diagnosis. Further clarification of the biological mechanisms of cancer progression could help to identify effective biomarkers for prognostication.
Malignant cells often have elevated metabolic rates than normal cells [5], and glucose is known to serve as a substrate and a regulator of metabolic pathways in cellular metabolism [6]. Glucose transporters are membrane transporter proteins that catalyze the facilitative bidirectional transfer of their substrates across membranes [7]. Glucose transporter-1 (GLUT-1) is the first identified member of glucose transporter family, and the most intensively studied of all membrane transport proteins [8]; it was reported to be overexpressed in various malignancies [9-11]. Previous studies [12-15] also showed the prognostic value of GLUT-1 expression in CRC; however, there was little consistency in the 
results that were presented. Limited sample sizes or other inconsistent study parameters could be the potential factors leading to these discrepant findings. Therefore, we collected all relevant studies and performed a quantitative meta-analysis to investigate the prognostic and clinical role of GLUT-1 in CRC. To our knowledge, this metaanalysis is the first one on this subject to date.

\section{RESULTS}

\section{Studies selection and characteristics}

Four hundred and forty-four records were identified through initial searching as described in the methods. After duplicate records were discarded, 345 records were left for screening, of which 300 records were then removed by title and/or abstract inspection. Forty-five records were further evaluated by full-text reading, and 31 studies were excluded either owing to being a meeting abstract $(n=1)$, lacking necessary information $(n=27)$, being duplicate studies $(n=1)$, or not using immunohistochemistry (IHC) methods $(n=2)$. Finally, 14 studies [12-25] published from 1998 to 2016 were included in the meta-analysis. The article selection process was shown in Figure 1. The included studies were from 10 countries with a total sample size of 2,077, and all studies used IHC to detect GLUT-1. Nine studies [12-14, 16, 18-20, 22, 25] recruited patients with CRC and 5 studies $[15,17,21,23$, $24]$ were performed on patients with rectal cancer (RC). Newcastle-Ottawa Scale (NOS) scores ranged from 7 to 9 , indicating that all included studies were high quality studies. The baseline characteristics of included studies were demonstrated in Table 1.

\section{GLUT-1 and overall survival}

Eight studies [13, 14, 16, 17, 19, 21, 22, 25] investigated the correlation of GLUT-1 expression and overall survival (OS) in a total of 1,526 patients. Owing to significant heterogeneity $\left(I^{2}=75.7 \%, \mathrm{P}_{\mathrm{h}}<0.001\right.$; Table 2$)$, a random-effects model was used. The results showed that there was no significant correlation between GLUT-1 expression and $\mathrm{OS}$ in $\mathrm{CRC}$ (Hazard ratio $[\mathrm{HR}]=1.28,95 \%$ confidence interval $[\mathrm{CI}]=0.86-1.91, \mathrm{p}=0.22$; Table 2 , Figure 2). To further investigate the connection of GLUT1 and OS, we conducted subgroup analyses. RC is a subtype of CRC and subgroup analysis on cancer types of $\mathrm{CRC}$ and $\mathrm{RC}$ was performed to clarify the specific role of GLUT-1 in RC. The pooled data demonstrated that GLUT1 still had no significant association with OS irrespective of location, cancer type, and treatment (Table 2).

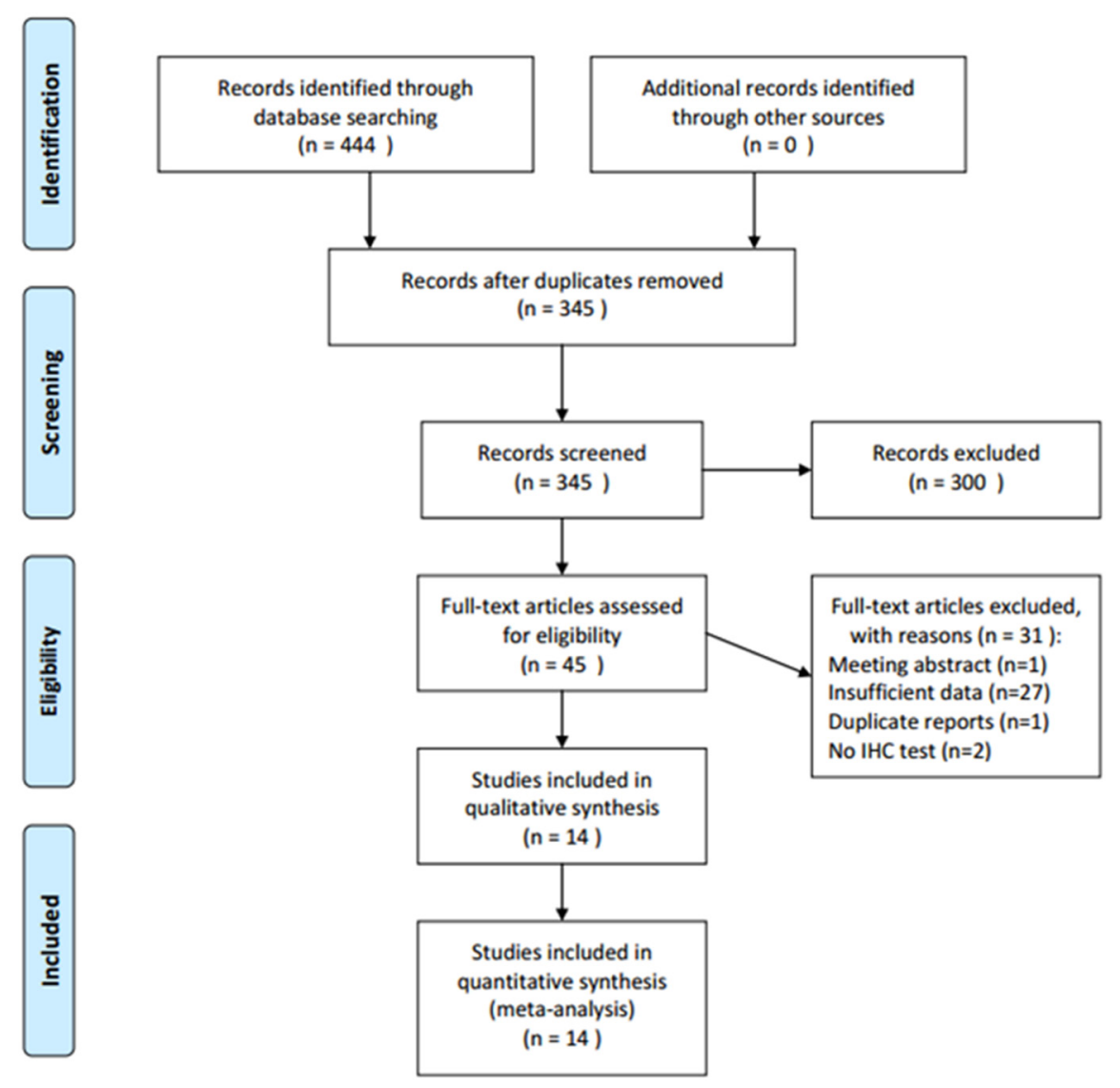

Figure 1: Flow diagram for articles included in this meta-analysis. 
Table 1: Basic information of included studies

\begin{tabular}{|c|c|c|c|c|c|c|c|c|c|}
\hline Study & Year & Country & $\begin{array}{c}\text { No. of } \\
\text { patients }\end{array}$ & $\begin{array}{c}\text { Sex } \\
(\mathbf{M} / \mathbf{F})\end{array}$ & $\begin{array}{c}\text { Cancer } \\
\text { type }\end{array}$ & Method & Treatment & $\begin{array}{l}\text { NOS } \\
\text { score }\end{array}$ & GLUT-1 (+) threshold \\
\hline Haber & 1998 & USA & 112 & $60 / 52$ & $\mathrm{CRC}$ & $\mathrm{IHC}$ & Surgical resection & 7 & Immunostaining $>50 \%$ \\
\hline Furudoi & 2001 & Japan & 152 & $94 / 58$ & CRC & $\mathrm{IHC}$ & Surgical resection & 8 & Immunostaining $>47.9 \%$ \\
\hline Cooper & 2003 & Turkey & 43 & $29 / 14$ & $\mathrm{RC}$ & $\mathrm{IHC}$ & Surgical resection & 7 & Immunostaining $>0 \%$ \\
\hline Yuan & 2003 & China & 42 & $24 / 18$ & CRC & $\mathrm{IHC}$ & Surgical resection & 7 & Immunostaining $>50 \%$ \\
\hline Zhou & 2005 & China & 60 & $32 / 28$ & $\mathrm{CRC}$ & IHC & Surgical resection & 9 & Immunostaining $>10 \%$ \\
\hline Cleven & 2007 & $\begin{array}{c}\text { The } \\
\text { Netherlands }\end{array}$ & 133 & $55 / 78$ & CRC & $\mathrm{IHC}$ & Surgical resection & 8 & Immunostaining $>5 \%$ \\
\hline Wincewicz & 2007 & Poland & 123 & $65 / 58$ & CRC & $\mathrm{IHC}$ & Surgical resection & 8 & Immunostaining $>10 \%$ \\
\hline Havelund & 2011 & Denmark & 86 & $49 / 37$ & $\mathrm{RC}$ & $\mathrm{IHC}$ & Chemoradiotherapy & 7 & Immunostaining $>50 \%$ \\
\hline Jun & 2011 & Korea & 515 & $293 / 222$ & CRC & $\mathrm{IHC}$ & Surgical resection & 8 & Immunostaining $>50 \%$ \\
\hline Korkeila & 2011 & Finland & 178 & $104 / 74$ & $\mathrm{RC}$ & $\mathrm{IHC}$ & Surgical resection & 8 & Immunostaining $>10 \%$ \\
\hline Hong & 2012 & Korea & 44 & $24 / 20$ & $\mathrm{RC}$ & $\mathrm{IHC}$ & Surgical resection & 7 & Immunostaining $>10 \%$ \\
\hline Lastraioli & 2012 & Italy & 135 & $63 / 72$ & $\mathrm{CRC}$ & $\mathrm{IHC}$ & Surgical resection & 7 & Immunostaining $>50 \%$ \\
\hline Shim & 2013 & Korea & 104 & $71 / 33$ & $\mathrm{RC}$ & $\mathrm{IHC}$ & Chemoradiotherapy & 7 & Immunostaining $>50 \%$ \\
\hline Goos & 2016 & $\begin{array}{l}\text { The } \\
\text { Netherlands }\end{array}$ & 350 & NR & $\mathrm{CRC}$ & $\mathrm{IHC}$ & Surgical resection & 8 & Immunostaining $>50 \%$ \\
\hline
\end{tabular}

Abbreviations: CRC, colorectal cancer; RC, rectal cancer; IHC: immunohistochemical staining; NOS, Newcastle-Ottawa Scale.

Table 2: Main results of meta-analysis for colorectal cancer

\begin{tabular}{|c|c|c|c|c|c|c|}
\hline \multirow{2}{*}{ Variables } & \multirow{2}{*}{$\begin{array}{c}\text { No. of } \\
\text { studies }\end{array}$} & \multirow{2}{*}{$\begin{array}{c}\text { Effects } \\
\text { model }\end{array}$} & \multirow{2}{*}{ HR $(95 \% C I)$} & \multirow{2}{*}{$\mathbf{p}$} & \multicolumn{2}{|c|}{ Heterogeneity } \\
\hline & & & & & $I^{2}(\%)$ & $\mathbf{P}_{\mathrm{h}}$ \\
\hline $\mathrm{OS}$ & 8 & Random & $1.28(0.86-1.91)$ & 0.22 & 75.7 & $<0.001$ \\
\hline \multicolumn{7}{|l|}{ Location } \\
\hline Western countries & 5 & Random & $1.11(0.61-2.03)$ & 0.734 & 82.5 & $<0.001$ \\
\hline Eastern countries & 3 & Random & $1.86(0.83-4.17)$ & 0.132 & 66.1 & 0.053 \\
\hline \multicolumn{7}{|l|}{ Cancer type } \\
\hline $\mathrm{CRC}$ & 6 & Random & $1.2(0.76-1.88)$ & 0.44 & 80.5 & $<0.001$ \\
\hline $\mathrm{RC}$ & 2 & Random & $2.06(0.53-7.96)$ & 0.294 & 63.8 & 0.097 \\
\hline \multicolumn{7}{|l|}{ Treatment } \\
\hline Surgical resection & 7 & Random & $1.31(0.83-2.06)$ & 0.244 & 79.2 & $<0.001$ \\
\hline Chemoradiotherapy & 1 & - & $1.21(0.63-2.33)$ & 0.568 & - & - \\
\hline DFS & 4 & Random & $1.71(0.78-3.72)$ & 0.179 & 61.8 & 0.049 \\
\hline \multicolumn{7}{|l|}{ Location } \\
\hline Western countries & 1 & - & $0.87(0.24-3.12)$ & 0.831 & - & - \\
\hline Eastern countries & 3 & Random & $2.16(0.75-6.18)$ & 0.152 & 73.5 & 0.023 \\
\hline \multicolumn{7}{|l|}{ Cancer type } \\
\hline $\mathrm{CRC}$ & 1 & - & $1.12(0.86-1.46)$ & 0.414 & - & - \\
\hline $\mathrm{RC}$ & 3 & Fixed & $2.47(1.21-5.05)$ & 0.013 & 46.4 & 0.155 \\
\hline \multicolumn{7}{|l|}{ Treatment } \\
\hline Surgical resection & 3 & Fixed & $1.13(0.87-1.46)$ & 0.364 & 0 & 0.476 \\
\hline Chemoradiotherapy & 1 & & $4.01(1.55-10.37)$ & 0.004 & - & - \\
\hline
\end{tabular}




\section{GLUT-1 and disease-free survival}

There were 4 studies [17, 22-24] with 840 subjects reporting the correlation between GLUT-1 expression and disease-free survival (DFS). Because of heterogeneity $\left(I^{2}=61.8 \%, \mathrm{P}_{\mathrm{h}}=0.049\right.$; Table 2$)$, randomeffects model was used for this calculation. The pooled
HR was 1.71 , with $95 \% \mathrm{CI}=0.78-3.72, \mathrm{p}=0.179$ (Table 2, Figure 3). Subgroup analyses were also performed, the results of which showed that GLUT-1 was significantly associated with shorter DFS in rectal cancer $(\mathrm{HR}=2.47,95 \% \mathrm{CI}=1.21-5.05, \mathrm{p}=0.013$, Table 2 , Figure 3). However, no significant association was found when stratified by location and treatment.

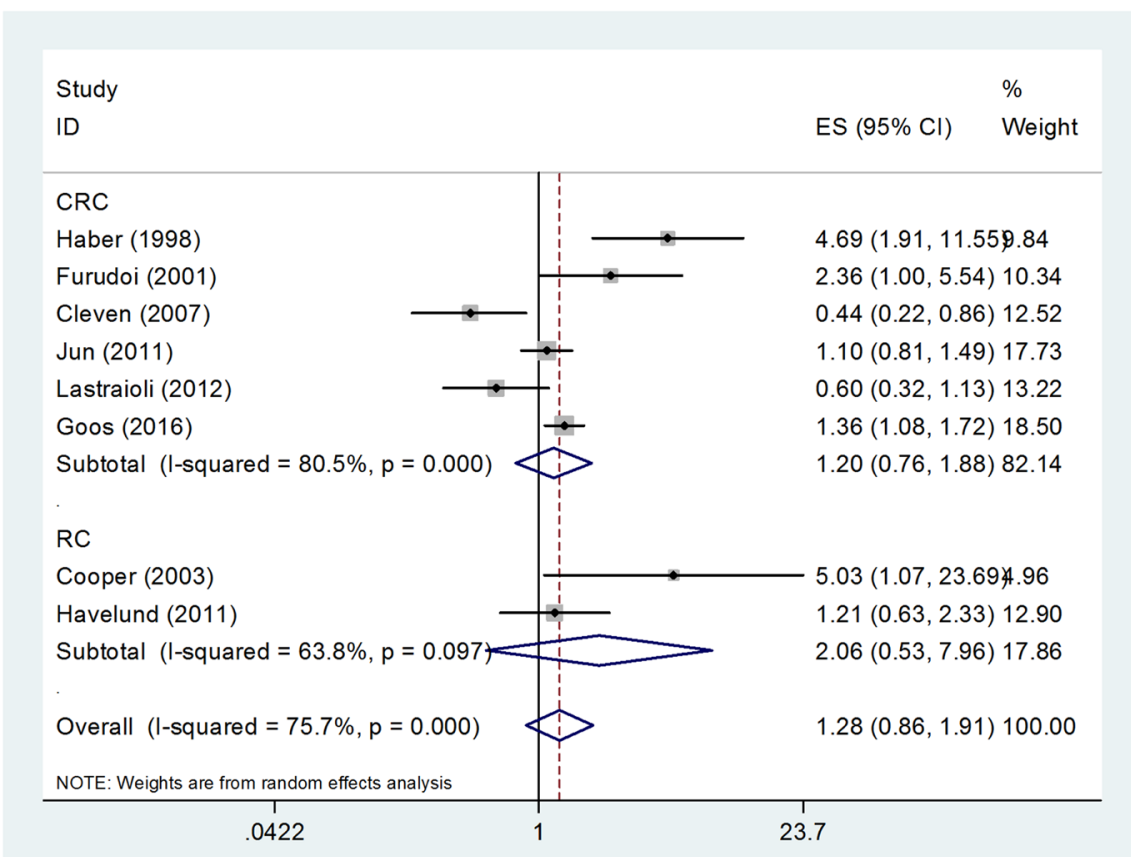

Figure 2: Forest plot diagrams of hazard ratios for correlations between GLUT-1 expression and OS. The forest plot was stratified by cancer type. The pooled HR and $95 \% \mathrm{CI}$ for OS were on the overall horizontal line. The horizontal axis indicates the pooled HR. ES (effect size) is HR in this figure.

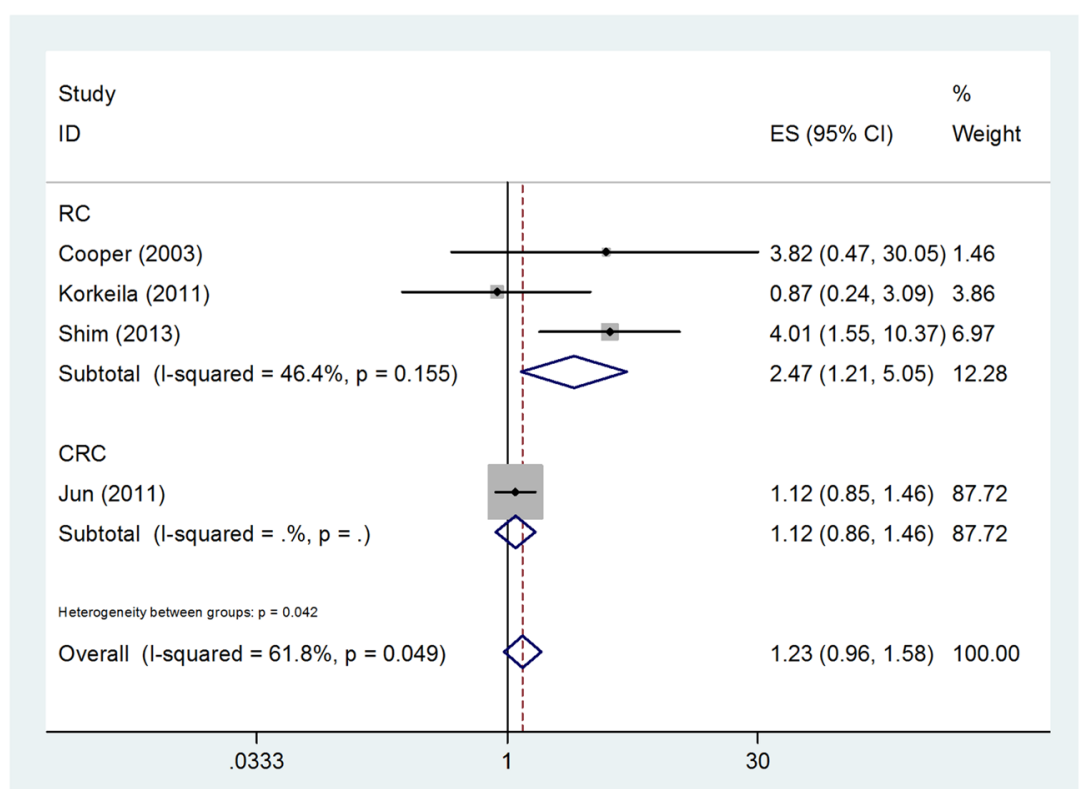

Figure 3: Forest plot diagrams of hazard ratios for correlations between GLUT-1 expression and DFS. The forest plot was stratified by cancer type. The pooled HR and $95 \%$ CI for DFS were on the overall horizontal line. The horizontal axis indicates the pooled HR. ES (effect size) is HR in this figure. 


\section{GLUT-1 and clinical features}

Nine studies [12, 13, 15, 16, 18, 20-22, 24] reported the association between GLUT-1 and clinical features. A total of 8 clinical features were investigated, which were age ( $\geq 60$ vs. $<60$ ), sex (female vs. male), lymph node metastasis (yes vs. no), differentiation (poor vs. moderate/ well), T stage (T3+T4 vs. T1+T2), Dukes stage (C+D vs. $A+B$ ), tumor size ( $\geq 5 \mathrm{~cm}$ vs. $<5 \mathrm{~cm}$ ), and liver metastasis (yes vs. no). The results showed that GLUT-1 expression was significantly correlated with presence of lymph node metastasis $(n=8, O R=2.14,95 \% \mathrm{CI}=1.66-2.75, \mathrm{p}<0.001$, Figure 4), $\mathrm{T}$ stage $(\mathrm{n}=6, \mathrm{OR}=1.73,95 \% \mathrm{CI}=1.17-2.58$,

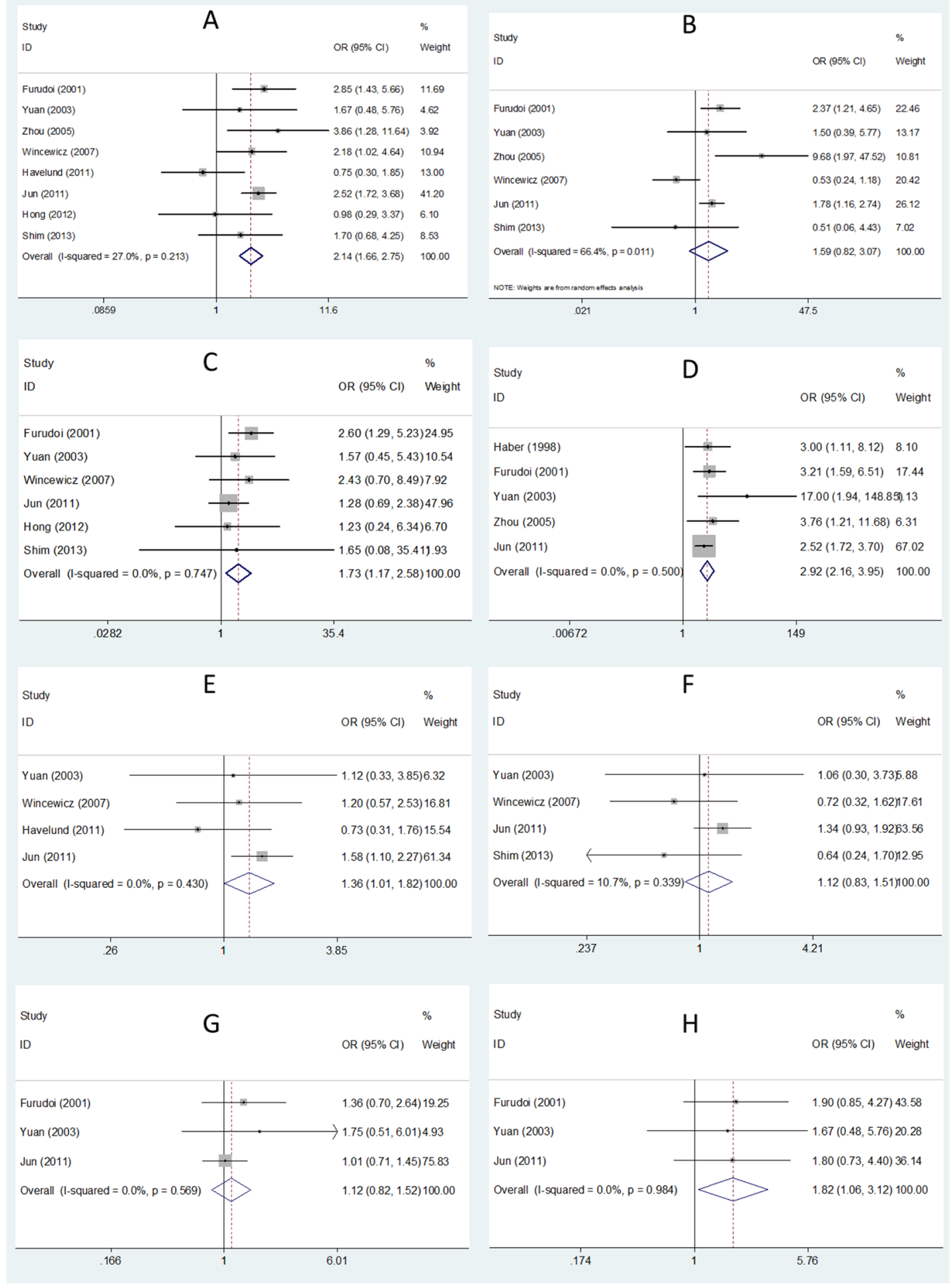

Figure 4: Association between GLUT-1 expression and clinicopathological parameters in CRC. A. lymph node metastasis; B. differentiation; C. T stage; D. Dukes stage; E. sex; F. age; G. tumor size; H. liver metastasis. 
$\mathrm{p}=0.007$, Figure 4), higher Dukes stage $(\mathrm{n}=5, \mathrm{OR}=2.92$, $95 \% \mathrm{CI}=2.16-3.95, \mathrm{p}<0.001$, Figure 4), female sex $(\mathrm{n}=4, \mathrm{OR}=2.92,95 \% \mathrm{CI}=2.16-3.95, \mathrm{p}<0.001$, Figure 4$)$, and presence of liver metastasis $(\mathrm{n}=3, \mathrm{OR}=1.82,95 \%$ $\mathrm{CI}=1.06-3.12, \mathrm{p}=0.03$, Figure 4). However, there was no significant connection between GLUT-1 and other clinical features including tumor differentiation $(n=6$, $\mathrm{OR}=1.59,95 \% \mathrm{CI}=0.82-3.07, \mathrm{p}=0.166$, Figure 4), age $(n=4, O R=1.12,95 \% C I=0.83-1.51, p=0.455$, Figure 4$)$, or tumor size $(n=3, O R=1.12,95 \% \mathrm{CI}=0.82-1.52, \mathrm{p}=0.48$, Figure 4).

\section{Publication bias}

Begg's test [26] and Egger's test [27] were used to detect potential publication bias. For OS, the $p$ values for Begg's test and Egger's test were 0.266 and 0.699, respectively (Figure 5). For DFS, Begg's p was 0.734 and Egger's p was 0.382, respectively (Figure 5). The results demonstrated that there was no evidence of significant bias in this meta-analysis, and therefore, our results were statistically reliable.

\section{DISCUSSION}

To our knowledge, the current meta-analysis was the first to investigate the prognostic significance of GLUT-1 expression in CRC. Our study demonstrated that GLUT-1 was associated with poor DFS in rectal cancer, but had a non-significant correlation with OS. Furthermore, GLUT1 overexpression was positively connected with lymph node metastasis, T stage, higher Dukes stage, female sex, and presence of liver metastasis. Taken together, these results indicated that GLUT-1 was a promising prognostic biomarker for shorter DFS and aggressive clinical parameters.

GLUT-1 mediates basal glucose transport in cancer cells and provides glucose for energy metabolism [28]. Inducing angiogenesis is a hallmark of cancer and is often correlated to cancer progression [5]. When cancer cells outgrow the existing vasculature, then hypoxia occurs, and as a result of this, cancer cells respond to hypoxic conditions through activating genes that are responsible for glucose transport [29]. Malignant cells require high energy levels to proliferate, and GLUT-1 was found to be overexpressed in various cancer types including prostate cancer, gastric cancer, breast cancer, head and neck cancer, and lung cancer [30]. Previous studies also showed that GLUT-1 overexpression was an indicator of poor prognosis in different cancers [11, 31-34]. The present meta-analysis identified GLUT1 as a significant biomarker for DFS in rectal cancer. Our results were in accordance with previous findings in other cancer types, and owing to the fact that no meta-analysis on GLUT-1 and prognosis of patients with cancer has been reported, we could not compare
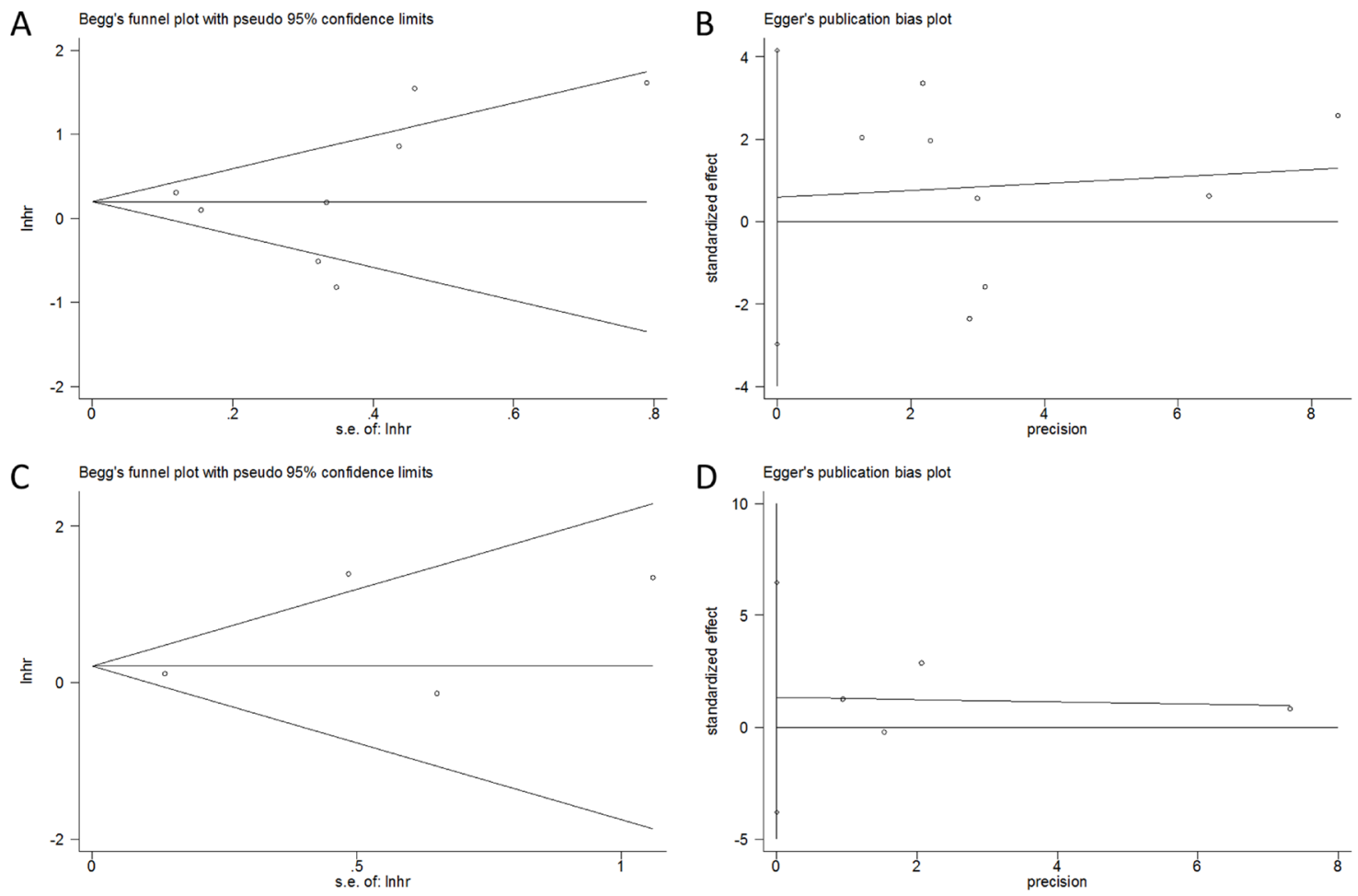

Figure 5: Publication bias in the meta-analysis. A. Begg's test for OS; B. Egger's test for OS; C. Begg's test for DFS; D. Egger's test for DFS. 
our results with other similar meta-analyses. We also found GLUT-1 was correlated with a variety of clinical parameters, which suggest that GLUT-1 could be a potential marker for aggressive biological behavior of cancer cells.

Several limitations still need to be acknowledged. First, significant heterogeneity among studies was detected on OS and DFS analyses. Although we selected eligible studies using uniform criteria, inherent differences among studies still existed. Second, the sample size was relatively small, where only four studies were included when the correlation between GLUT-1 and DFS was analyzed. Although Begg's test and Egger's test suggested nonsignificant publication bias, selection bias could be possibly exist owing to limited sample size.

In conclusion, this meta-analysis showed that GLUT-1 was associated with poor DFS in rectal cancer. In addition, GLUT-1 was also an indicator of aggressive clinical features in CRC. Because several limitations exist in this study, further investigations are required to warrant our findings.

\section{MATERIALS AND METHODS}

\section{Search strategy and study selection}

This meta-analysis was carried out in line with the Preferred Reporting Items for Systematic Reviews and Meta-Analyses (PRISMA) statement [35]. Electronic platforms of PubMed, Embase, Web of Science, and China National Knowledge Infrastructure (CNKI) were thoroughly searched to September 8, 2016. The search items were as follows: "Glucose transporter-1", "GLUT1", "SLC2A1", "colorectal cancer", "colon cancer", "rectal cancer", and "; colorectal neoplasms"[MeSH Terms]. The reference lists of all retrieved articles were screened to identify other relevant studies. The inclusion criteria in the meta-analysis were as follows: (1) studies investigating the association between GLUT-1 expression and survival outcomes or clinical features; (2) studies where the diagnosis of CRC was confirmed via pathology reports; (3) studies that reported patients with either colorectal cancer or colon cancer or rectal cancer; (4) studies where the hazard ratios (HRs) and 95\% confidence intervals (CIs) for survival analysis were directly reported or could be calculated using Parmar's methods [36]; (5) studies measuring GLUT-1 expression via immunohistochemistry (IHC); and (6) studies published as full-text articles in either English or Chinese. Exclusion criteria were: (1) reviews, case reports, letters, and meeting abstracts; (2) studies not using IHC to detect GLUT-1; (3) studies lacking necessary data for calculation.

\section{Data extraction and quality assessment}

Two independent investigators extracted the following information from eligible studies: first author's name, year of publication, study country, sample size, sex, cancer type, detection method, treatment methods, and research period. Discrepancies between the two investigators were resolved by discussion. The qualities of included studies were evaluated by using NOS [37]. The NOS assessed a study on three aspects: selection (4 stars), comparability ( 2 stars), and outcome ( 3 stars). The maximal score is 9 stars and studies with $\geq 7$ stars were assigned as high quality studies.

\section{Statistical analysis}

All statistical analyses were performed using Stata 12.0 (Stata Corporation, College Station, TX, USA). HRs and $95 \%$ CIs were used to evaluate the effect of GLUT1 expression on overall survival (OS) and disease-free survival (DFS) in CRC patients. HR >1 without 95\% CI overlapping 1 indicates a significant association between high GLUT-1 expression and poor outcomes. Heterogeneity among studies was tested using Cochran Q and $I^{2}$ statistics. If $\mathrm{p}$-value for heterogeneity $\left(\mathrm{P}_{\mathrm{h}}\right)<0.10$ and $I^{2}>50 \%$ indicate significant heterogeneity, then a randomeffects model was used; otherwise, a fixed-effects model was utilized. For further analysis, subgroup analyses according to location, cancer type, and treatment were conducted. Odds ratios (ORs) and 95\% CIs were used to calculated the relevance of GLUT-1 and clinical features. Publication bias was tested by using Begg's funnel plot test [26] and Egger's test [27]. $\mathrm{P}<0.05$ was considered as statistically significant.

\section{CONFLICTS OF INTEREST}

The authors confirm that there are no conflicts of interest.

\section{GRANT SUPPORT}

This work was supported by a grant from Natural Science Foundation of Hainan Province (No. 20168355).

\section{REFERENCES}

1. Torre LA, Bray F, Siegel RL, Ferlay J, Lortet-Tieulent J, Jemal A. Global Cancer Statistics, 2012. CA Cancer J Clin. 2015; 65:87-108.

2. Ferlay J, Soerjomataram I, Dikshit R, Eser S, Mathers C, Rebelo M, Parkin DM, Forman D, Bray F. Cancer incidence and mortality worldwide: sources, methods and major patterns in GLOBOCAN 2012. Int J Cancer. 2015; 136:E359-386.

3. Weitz J, Koch M, Debus J, Hohler T, Galle PR, Buchler MW. Colorectal cancer. Lancet. 2005; 365:153-165.

4. Siegel R, Desantis C, Jemal A. Colorectal cancer statistics, 2014. CA Cancer J Clin. 2014; 64:104-117. 
5. Hanahan D, Weinberg RA. Hallmarks of cancer: the next generation. Cell. 2011; 144:646-674.

6. Thorens B, Mueckler M. Glucose transporters in the 21st Century. Am J Physiol Endocrinol Metab. 2010; 298:E141-145.

7. Saier MH, Jr., Beatty JT, Goffeau A, Harley KT, Heijne WH, Huang SC, Jack DL, Jahn PS, Lew K, Liu J, Pao SS, Paulsen IT, Tseng TT, Virk PS. The major facilitator superfamily. J Mol Microbiol Biotechnol. 1999; 1:257-279.

8. Carruthers A, DeZutter J, Ganguly A, Devaskar SU. Will the original glucose transporter isoform please stand up! Am J Physiol Endocrinol Metab. 2009; 297:E836-848.

9. Kunkel M, Reichert TE, Benz P, Lehr HA, Jeong JH, Wieand S, Bartenstein P, Wagner W, Whiteside TL. Overexpression of Glut-1 and increased glucose metabolism in tumors are associated with a poor prognosis in patients with oral squamous cell carcinoma. Cancer. 2003; 97:1015-1024.

10. Sasaki H, Shitara M, Yokota K, Hikosaka Y, Moriyama S, Yano M, Fujii Y. Overexpression of GLUT1 correlates with Kras mutations in lung carcinomas. Mol Med Rep. 2012; 5:599-602.

11. Maki Y, Soh J, Ichimura K, Shien K, Furukawa M, Muraoka T, Tanaka N, Ueno T, Yamamoto H, Asano H, Tsukuda K, Toyooka S, Miyoshi S. Impact of GLUT1 and Ki-67 expression on earlystage lung adenocarcinoma diagnosed according to a new international multidisciplinary classification. Oncol Rep. 2013; 29:133-140.

12. Yuan HZ, Zhan BL, Zhang GL. Expression of Glut1 and MVD in colorectal carcinoma and its relationship with liver metastasis. China Cancer. 2003; 59-61.

13. Furudoi A, Tanaka S, Haruma K, Yoshihara M, Sumii K, Kajiyama G, Shimamoto F. Clinical significance of human erythrocyte glucose transporter 1 expression at the deepest invasive site of advanced colorectal carcinoma. Oncology. 2001; 60:162-169.

14. Lastraioli E, Bencini L, Bianchini E, Romoli MR, Crociani O, Giommoni E, Messerini L, Gasperoni S, Moretti R, Di Costanzo F, Boni L, Arcangeli A. hERG1 Channels and Glut-1 as Independent Prognostic Indicators of Worse Outcome in Stage I and II Colorectal Cancer: A Pilot Study. Transl Oncol. 2012; 5:105-112.

15. Hong R, Lim SC. (1)(8)F-fluoro-2-deoxyglucose uptake on PET CT and glucose transporter 1 expression in colorectal adenocarcinoma. World J Gastroenterol. 2012; 18:168-174.

16. Haber RS, Rathan A, Weiser KR, Pritsker A, Itzkowitz SH, Bodian C, Slater G, Weiss A, Burstein DE. GLUT1 glucose transporter expression in colorectal carcinoma: a marker for poor prognosis. Cancer. 1998; 83:34-40.

17. Cooper R, Sarioglu S, Sokmen S, Fuzun M, Kupelioglu A, Valentine H, Gorken IB, Airley R, West C. Glucose transporter-1 (GLUT-1): a potential marker of prognosis in rectal carcinoma? Br J Cancer. 2003; 89:870-876.
18. Zhou YL, Deng CS. Correlations of expressions of Glut1 and HIF-1alpha to cellular proliferation of colorectal adenocarcinoma. Chin J Cancer. 2005; 24:685-689.

19. Cleven AH, van Engeland M, Wouters BG, de Bruine AP. Stromal expression of hypoxia regulated proteins is an adverse prognostic factor in colorectal carcinomas. Cell Oncol. 2007; 29:229-240.

20. Wincewicz A, Sulkowska M, Koda M, Sulkowski S. Clinicopathological significance and linkage of the distribution of HIF-1alpha and GLUT-1 in human primary colorectal cancer. Pathol Oncol Res. 2007; 13:15-20.

21. Havelund BM, Sorensen FB, Lindebjerg J, Spindler KL, Jakobsen A. Pretreatment HIF-1alpha and GLUT-1 expressions do not correlate with outcome after preoperative chemoradiotherapy in rectal cancer. Anticancer Res. 2011; 31:1559-1565.

22. Jun YJ, Jang SM, Han HL, Lee KH, Jang KS, Paik SS. Clinicopathologic significance of GLUT1 expression and its correlation with Apaf-1 in colorectal adenocarcinomas. World J Gastroenterol. 2011; 17:1866-1873.

23. Korkeila EA, Sundstrom J, Pyrhonen S, Syrjanen K. Carbonic anhydrase IX, hypoxia-inducible factor-1alpha, ezrin and glucose transporter-1 as predictors of disease outcome in rectal cancer: multivariate Cox survival models following data reduction by principal component analysis of the clinicopathological predictors. Anticancer Res. 2011; 31:4529-4535.

24. Shim BY, Jung JH, Lee KM, Kim HJ, Hong SH, Kim SH, Sun DS, Cho HM. Glucose transporter 1 (GLUT1) of anaerobic glycolysis as predictive and prognostic values in neoadjuvant chemoradiotherapy and laparoscopic surgery for locally advanced rectal cancer. Int J Colorectal Dis. $2013 ; 28: 375-383$.

25. Goos JA, de Cuba EM, Coupe VM, Diosdado B, DelisVan Diemen PM, Karga C, Belien JA, Menke-Van der Houven van Oordt CW, Geldof AA, Meijer GA, Hoekstra OS, Fijneman RJ. Glucose Transporter 1 (SLC2A1) and Vascular Endothelial Growth Factor A (VEGFA) Predict Survival After Resection of Colorectal Cancer Liver Metastasis. Ann Surg. 2016; 263:138-145.

26. Begg CB, Mazumdar M. Operating characteristics of a rank correlation test for publication bias. Biometrics. 1994; 50:1088-1101.

27. Egger M, Davey Smith G, Schneider M, Minder C. Bias in meta-analysis detected by a simple, graphical test. BMJ. 1997; 315:629-634.

28. Kallinowski F, Schlenger KH, Runkel S, Kloes M, Stohrer M, Okunieff P, Vaupel P. Blood flow, metabolism, cellular microenvironment, and growth rate of human tumor xenografts. Cancer Res. 1989; 49:3759-3764.

29. Chiche J, Brahimi-Horn MC, Pouyssegur J. Tumour hypoxia induces a metabolic shift causing acidosis: a common feature in cancer. J Cell Mol Med. 2010; 14:771-794. 
30. Carvalho KC, Cunha IW, Rocha RM, Ayala FR, Cajaiba MM, Begnami MD, Vilela RS, Paiva GR, Andrade RG, Soares FA. GLUT1 expression in malignant tumors and its use as an immunodiagnostic marker. Clinics (Sao Paulo). 2011; 66:965-972.

31. Smith TA. Facilitative glucose transporter expression in human cancer tissue. Br J Biomed Sci. 1999; 56:285-292.

32. Minami K, Saito Y, Imamura H, Okamura A. Prognostic significance of p53, Ki-67, VEGF and Glut-1 in resected stage I adenocarcinoma of the lung. Lung Cancer. 2002; 38:51-57.

33. Harshani JM, Yeluri S, Guttikonda VR. Glut-1 as a prognostic biomarker in oral squamous cell carcinoma. J Oral Maxillofac Pathol. 2014; 18:372-378.
34. Ayala FR, Rocha RM, Carvalho KC, Carvalho AL, da Cunha IW, Lourenco SV, Soares FA. GLUT1 and GLUT3 as potential prognostic markers for Oral Squamous Cell Carcinoma. Molecules. 2010; 15:2374-2387.

35. Moher D, Liberati A, Tetzlaff J, Altman DG. Preferred reporting items for systematic reviews and meta-analyses: the PRISMA statement. PLoS Med. 2009; 6:e1000097.

36. Parmar MK, Torri V, Stewart L. Extracting summary statistics to perform meta-analyses of the published literature for survival endpoints. Stat Med. 1998; 17:2815-2834.

37. Stang A. Critical evaluation of the Newcastle-Ottawa scale for the assessment of the quality of nonrandomized studies in meta-analyses. Eur J Epidemiol. 2010; 25:603-605. 